\title{
La perspectiva Mapu de espacios judiciales y el pensamiento geográfico Mapuche ${ }^{1}$
}

\section{The Mapu perspective of judicial spaces and Mapuche geographical thinking}

\section{Leonarda De La Ossa Arias}

Universidad Federal de Espírito Santo

leonardaossa@gmail.com

https://orcid.org/0000-0002-3648-6482

\section{RESUMEN}

El artículo explora la perspectiva Mapu a partir de una inmersión etnográfica con $\mathrm{Pu}^{2}$ Mapuche en torno a un espacio judicial que se mueve en relación de antagónismo con los espacios geográficos en plural, presentando tensiones que dan apertura a otras geografías no hegemónicas, que escapan a la centralidad de reivindicar a la geografía como la ciencia del espacio del hombre, desplazando la reflexión, hacia la coexistencia de los seres y todas las formas de vida de y en los espacios, como dicho y practicado por los pensadores de pueblos originarios Quidel (2012), Melin et al (2017).

\begin{abstract}
The article explores the Mapu perspective, from an ethnographic immersion with Pu Mapuche, around a judicial space, which moves in an antagonistic relation with the geographical spaces in the plural, presenting tensions that open up other non-hegemonic geographies, which they escape the centrality of vindicating geography as the science of the space of man, displacing reflection, towards the coexistence of the beings and all forms of life of and in the spaces, as said and practiced by the thinkers of indigenous peoples Quidel (2012), Melin et at (2017).
\end{abstract}

\section{PALABRAS CLAVE:}

multidimensionalidad; construcción de espacios; coexistencia de distintas formas de vida; retomada; autonomía.

\section{KEYWORDS:}

multidimensionality; construction of spaces; coexistence of different forms of life; resumption; autonomy.

1 El presente artículo hace parte de la presentación de resultados parciales de la investigación de maestría en geografía denominada "Más allá del uno y de la ciencia del espacio del hombre, interlocución con la coexistencia de todas las formas de vida en y de los espacios". Agradezco el apoyo brindado para cursar la maestría en geografía período 20172019 en la Universidad Federal de Espírito Santo en Brasil a la Coordinación de perfeccionamiento de personal de nivel superior - CAPES. El trabajo de campo previo al año 2017 y posterior ha sido financiado en su totalidad por la autora de forma independiente y autogestionada.

$2 \mathrm{Pu}$ es un pluralizador en Mapudungun en la lengua Mapuche, siempre que aparezca quiere decir que me refiero al plural. 


\section{Introducción al espacio judicial}

En el presente artículo se exploran a partir de la perspectiva Mapu (Quidel, 2012; Melin et al., 2017) las tensiones entre las geografías estatales y las geografías ameríndias (Di Giminiani,2015) a partir de cómo en el espacio judicial (Le Bonniec, 2018) es decir en cárceles y tribunales en lo que hoy conocemos como Chile, se posibilita una interlocución con la geografía, la etnología y la historia, haciendo emerger enunciados espaciales cuando se llevan a cabo los juicios. Los cuales son enunciados espaciales que se entienden en el centro del antagónismo conceptual entre las prácticas espaciales estatales y las de los pueblos que se afirman de originarios (Di Giminiani, 2011; 2013; 2015).

El interés principal de la investigación de la cual este artículo presenta resultados parciales es la forma en que en el espacio judicial se posicionan las tensiones, antagónismos y equívocos mediante la observación de los repertorios usados tanto por $\mathrm{Pu}$ Mapuche así como por quienes hacen la defensa de $\mathrm{Pu}$ Mapuche, en contraste con aquellos que interponen las querellas, que en su mayoría son el Estado y las empresas forestales presentes en el que $P u$ Mapuche reclaman como el territorio ancestral Mapuche.

La caminada metodológica ${ }^{3}$ estuvo centrada en lo que sucede en los juicios en donde se está juzgando a alguien que es considerado de Preso Político Mapuche por su pueblo, aunque el mismo sea nombrado por el Estado como "comunero" o por su nombre propio, pero nunca desde el Estado nación y las autoridades se refiere como Presos políticos Mapuche, siendo este último un concepto Mapuche para referirse a $\mathrm{Pu}$ Mapuche que se reivindican como pagando los costos del proceso de reconstrucción como pueblo nación y por lo tanto posicionándose como siendo parte del territorio ancestral Mapuche. Donde el territorio ancestral Mapuche está compuesto también por los Presos Políticos Mapuche.

En el espacio judicial se experimentan las tensiones y equívocos epistemológicos y ontológicos y emerge un pensamiento geográfico Mapuche, que habla de la geografía de la vida y de lo que se profundiza en el artículo como una mirada del espacio geográfico siendo las ontologías de los seres de y en los espacios, haciendo emerger el concepto Mapuche de coexistencia de las diferentes formas de vida en y de los espacios que se construyen, en tanto se establecen relaciones entre distintas formas de vida, como lo dicho en las investigaciones del Longko y antropólogo José Quidel (2012) y reafirmado por la Alianza Territorial Mapuche - ATM en el año 2017 (Melin et al., 2017), en donde ambos reafirman el carácter vidacéntrico de las experiencias $P u$ Mapuche que hoy sustentan el que Pu Mapuche reclaman como el territorio ancestral Mapuche.

Entendemos y proponemos el concepto del espacio judicial/jurídico, como donde se llevan a cabo en medio de una organización socio - política específica, como a la que remite el Estado nación de tipo representativa las demandas Pu Mapuche que a su vez huyen de la lógica Estato céntrica, como las demandas que son colocadas en el debate público por el Pueblo Mapuche en lo que hoy conocemos como Chile y Argentina y que son llevadas a tribunales y contextos judiciales y jurídicos en donde emerge el Preso Político Mapuche como siendo desde Pu Mapuche parte del territorio ancestral Mapuche como fue mencionado anteriormente.

\footnotetext{
3 Con posterioridad al juicio que tomo como fuente principal de los análisis que componen el artículo, estuve en el mes de noviembre del año 2015, realizando entrevistas a distintos Pu Mapuche, apoyadores, académicos, redes de solidaridad vinculadas con la conocida como la prisión política Mapuche. Las entrevistas formales fueron realizadas de forma autogestionada e independiente por la autora y por Álvaro Revenga Herrán, en el marco de una propuesta de documental que queríamos llevar a cabo en ese momento, sin embargo, no uso nada del contenido de esas entrevistas para el presente artículo, limitándome principalmente al material de los juicios que estuve acompañando sin ninguna compañía más que la de $\mathrm{Pu}$ Mapuche y apoyadores que iba encontrando y conociendo en el proceso.
} 
Las experiencias del pueblo Mapuche hoy nos sitúan en la necesidad de observar en la jurisdicción de los Estados nacionales como Chile y Argentina y en los juicios y tribunales, cómo son constantemente abiertas las tensiones pero sobretodo heridas que hablan no solo de genocidio sino en los términos de Clastres [1980] (2004), Viveiros (2004; [2009] 2018) y Contreras Painemal (2008) nos provoca a aproximarnos a una experiencia de etnocidio ${ }^{4}$, como el descrito por Clastres [1980] (2004) y retomado por las obras de Viveiros de Castro, Marcio Goldman y Tania Stolze Lima principalmente.

\section{Despojo de $P$ u newen}

A finales del siglo XIX un acto administrativo tras operaciones militares despojó y dejó de las 10`000,000 de hectáreas del territorio ancestral Mapuche aproximadamente unas 500,000 hectáreas (Millalén, 2006; Correa y Mella 2009). El acto administrativo se conoce como proceso de radicación ${ }^{5}$ de comunidades y se dio mediante la entrega de títulos de comisarios y títulos de merced, como fueron llamadas las reservas indígenas, en el marco de la expansión del frente colonial del Estado nación chileno y la ampliación de su frontera agrícola, siendo concedidas unas "reservas de tierras" para $P$ u Mapuche, quienes eran considerados por el Estado a su vez como incapacitados para gobernarse y barbaros (Vera, 1905).

Se emprendieron como política de Estado nación procesos de desterritorialización en términos de prácticas espirituales siendo que el constante contacto e incursión de misiones religiosas, principalmente la anglicana y franciscana (Quidel, 2012) junto con la Escuela y los procesos de educación y la enseñanza a cargo de la Iglesia se constituyeron en factores imperativos al forzar a $\mathrm{Pu}$ Mapuche a la incorporación en un ordenamiento socio político y territorial como al que remite el Estado nación.

Con el despojo se fueron desplazando los Futal Mapu o las que se reivindican hoy por Pu Mapuche como identidades territoriales (Quidel, 2012; Melin et al., 2017) cobrando sentido lo señalado por el historiador Martin Correa en el peritaje histórico que presentó ante un Tribunal que transcribo a continuación:

Según las memorias del propio Cornelio Saavedra, estas mismas tierras que fueron insisto, pérdidas, y que fueron usurpadas legalmente, más no legítimamente, porque no se les reconoce la ocupación ancestral de este territorio, son nuevamente recuperadas en el proceso de reforma agraria, osea tenemos un Estado que en algún momento ocupa militarmente luego reduce territorialmente y luego reconoce el dominio a través del proceso de reforma agraria y devuelve el uso, hasta ese momento, hasta el golpe, hasta ahí nada más llegó el proceso de recuperación, no se alcanza a reconocer el dominio y es el mismo Estado, insito, reduce, ocupa, radica, de ahí al poco tiempo llegan las empresas forestales, quienes compran los derechos, el dominio de los predios en cuestión, por esto quiero señalar que en realidad, la realidad de los papeles puede estar en ley, pero la realidad legitimidad del origen del dominio, en norma, no existe en este caso, por último quisiera señalar que lo que yo estoy diciendo hoy en día forma parte de la memoria, de la tradición comunitaria, no como un asunto solamente cultural en términos de la tradición folclórica, sino también de las vivencias, de las comunidades cotidianas, de las conversaciones de los Longko ${ }^{6}$. (Grifo mío)

En consecuencia con el histórico de despojo presentado por Martin Correa se debe mencionar que en los Estados nacionales de Chile y Argentina, no existe un reconocimiento a formas propias $P u$ Mapuche, de ejercicio y administración de justicia, derivado de que no existe un reconocimiento, más allá del carácter de "etnia" como ocurre en Chile, a un sistema político ameríndio Mapuche, donde el $A z$

4 En el campo del audiovisual sobre pueblos originarios, la cineasta colombiana del movimiento del cine político de América Latina, Marta Rodríguez Otero, hizo en el año 2011 el documental titulado "Téstigos de un etnocidio".

5 CHILE. Ley de radicación. s/n do 4 de dezembro de 1866. Biblioteca Nacional do Congresso da República. Disponível em: hyps:// www.leychile.cl/Navegar? idNorma=1045956

6 Registro realizado junto a Vicente Montecinos. 
Mapu, más que considerado como un dato exótico y curioso, sea reconocido como un sistema de normas y procedimientos (Melin et al., 2015), que se enmarcan en la vivencia de un sistema de ordenamiento jurídico propio Mapuche, que permite administrar las relaciones que se establecen entre humanos, no humanos, ancestros humanos, animales, vegetales, que se encuentran en el concepto de ixofillmogen, como la coexistencia de todas las formas de vida, tal como ha sido bien profundizado por la Alianza Territorial Mapuche - ATM (Quidel, 2012; Melin y otros, 2017; Curamil, 2019).

Así también y en conexión con lo anterior, el historiador Martin Correa señaló ante las preguntas del Tribunal referidas a la administración de justicia en el pueblo Mapuche lo siguiente:

Pregunta: En ese orden de ideas cómo se aplicaba la justicia para el pueblo Mapuche, antes de la constitución del estado chileno?

Pero antes de la constitución del estado chileno estamos hablando de un territorio autónomo, era justicia al interior de la comunidad.

Quién la ejercía?

La ejercían las autoridades, los Longko

Cómo se fueron adaptando a la justicia cuando se establece el estado Chileno?

A la fuerza.

A la fuerza, de qué forma, por qué indica a la fuerza?

Por ejemplo, porqué de repente estamos en presencia de un territorio en el cual habia una ocupación amplia en que se reconocian los deslindes, por ejemplo hay un elemento fundamental y es que las familias y los lof antiguos, colindaban con accidentes geográficos, ríos, quebradas, el título de merced de polma por ejemplo habla de una línea recta de no se cuántos grados que no son las líneas antiguas, entonces de alguna forma cuando el ejército chileno ingresa a la Araucanía y se hace el Estado chileno de estos territorios es a la fuerza, en palabras del ministerio de guerra no es que yo lo diga, también, a la fuerza son entregadas las tierras, también a la fuerza son usurpadas las tierras, también a la fuerza cuando hubo el proceso de reforma agraria que también es a la fuerza de nuevo el golpe, insisto, no es un gobierno, es el Estado chileno, que dice de acuerdo a estas tierras fueron porque tenían más de 80 hectáreas de riego básico y toda la normativa de la ley 16640 o de reforma agraria usted tienen derecho a ocupar este territorio, hay convenios con la CONAF para trabajos en el territorio y nuevamente son despojados del territorio y son devueltos a la familia y de ahi pasan a las forestales.

Las investigaciones que abordan el espacio judicial y jurídico en contraste con las inmersiones que hemos realizado nos permiten hablar de un espacio judicial en donde emergen las tensiones entre el Estado nación y el pueblo Mapuche, pero en el cual también emergen estrategias $\mathrm{Pu}$ Mapuche que practican lo que el dicho de pensamiento moderno llama de política, en una constante tensión entre hacer una política Wingka o hacer una política que escuche y se guie por los ancestrales, referidos en los tribunales como Pu Longko.

Por lo anterior y en contraste, privilegiamos lo experimentado en el espacio judicial de primera fuente, principalmente los juicios que suceden en Tribunales, considerando que nuestra intención y el trabajo de campo estuvo guíado por seguir tanto in situ como a través de la revisión documental la emergencia del preso político Mapuche como un concepto Mapuche que surge para hacer frente a equívocos que el espacio judicial coloca, por ejemplo; al Estado nación denominar de comuneros a los miembros $\mathrm{Pu}$ Mapuche, que son considerados por colectivos $\mathrm{Pu}$ Mapuche, como presos políticos 
Mapuche, en tanto las causas de su prisión se encuentran relacionadas con el que $\mathrm{Pu}$ Mapuche refieren como el proceso de reconstrucción como pueblo nación.

El espacio judicial es un espacio de lucha, sobretodo y por lo experimentado en las interlocuciones que se dieron en el mismo al verificarse que $\mathrm{Pu}$ Mapuche son constantemente obligados no solamente a recordar y elaborar declaraciones de defensa de lo que llaman de restitución del territorio ancestral y de la recuperación como pueblo nación, sino que $\mathrm{Pu}$ Mapuche, son obligados a insertarse en las lógicas del Estado nación, su sistema jurídico, para buscar salidas posibles, desde la especificidad de ser un pueblo originario, que se siente amparado por muchas normativas, tanto nacionales e internacionales, cuyas demandas están insertas en últimas en lo que presenta Alexander Surrallés al señalar que las relaciones sociales que los pueblos dichos de originarios establecen con los no humanos, "les permite ejercer sus derechos actuales como pueblos indígenas en el derecho internacional” (Surrallés, 2017: 211).

La sujeción de los cuerpos $P u$ Mapuche al espacio judicial, no es experimentado por los Presos políticos Mapuche como una condena, porque el mismo hecho de que el Estado "sujete" al pueblo Mapuche a la jurisdicción del Estado chileno, es advertido en el espacio judicial por $\mathrm{Pu}$ Mapuche como una de las tantas pruebas del despojo, que si bien es cierto, se acerca y confluye con muchos de los postulados de Harvey (2004) sobre el proceso de acumulación por desposesión siendo el despojo al cual Pu Mapuche están refiriéndose se sitúa en el contexto de instalación de monocultura (Nahuelpan, 2013) como un despojo que afecta principalmente a $P u$ newen, que según los caminos recorridos en ese espacio judicial y desde $P u$ Mapuche que se han aproximado desde la escritura a la cuestión, el despojo de $P u$ Newen se acerca a lo que emergió en el tribunal cuando un testigo Mapuche se refirió de la siguiente forma:

Hoy en día el gran problema que tiene la tierra como espacio, ese encuentro a través de los Nguillatún, para restablecer el equilibrio de la tierra, sobre el problema grande que tiene la tierra y que es en relación a la sobreexplotación de sus recursos, de su newen, la fertilidad de la tierra, mientras más sobreexplotación exista más problemas va a tener, más debilidad va a tener la tierra, por eso es importante como lo hacían nuestros mayores ancianos antiguamente, como lo hacian las generaciones que pasaron y como lo seguimos haciendo los mapuche hoy en día tiene relación con restablecer el equilibrio que hemos ido perdiendo y ese equilibrio lamentablemente no hemos sido los mapuche que lo hemos ido generando, ese equilibrio que se ha ido perdiendo, las energías de la tierra que le llamamos newen, todo ese complemento espiritual que nosotros le llamamos kalfunewen, todo ese accionar que tiene la tierra en relación a lo que nosotros somos como esencia, como hijos de la tierra, ese es el concepto que hoy en día nosotros hemos seguido haciendo a través de Nguillatun.

Para un pueblo que se auto identifica como el pueblo Mapuche, no es antojadizo moverse en un fondo donde son considerados $P u$ Mapuche como insertos en la nacionalidad 'chilena' , donde en este caso la autonomía es entendida como una demanda, que viene siendo trabajada desde dentro de los pueblos originarios, y donde particularmente el pueblo Mapuche ha trabajado reflexiones, que justamente a lo que apuntan, es a aclarar que $P u$ Mapuche no están buscando independencia del Estado chileno, sino que es una operación diferente y se desconocen sus consecuencias, porque enmarcados dentro del derecho de la autodeterminación, $\mathrm{Pu}$ Mapuche están exigiendo un pacto político que así lo permita, como bien ha sido señalado por (Pairican, 2014, 2018; Pineda, 2013; Arrate y Llaitul, 2012) insertando Pu Mapuche sus demandas en el campo de las herramientas del derecho que les amparan.

Se desconocen sus consecuencias, porque hasta que no exista efectivamente la interlocución con el Estado chileno sobre el despojo y el etnocidio vistos desde una mirada Mapuche, se carece de condiciones para que la conversación sea posible, como lo señalado en diversos espacios por $\mathrm{Pu}$ Mapuche y siendo en contraste presentado el 
concepto Mapuche de Kisugünewi como el auto gobernarse, que subyace y se mantiene como paño de fondo a las demandas que distintos colectivos Pu Mapuche hoy están levantando en nombre de la autodeterminación.

El rechazo del Estado nación a conversar sobre el despojo, visto desde el punto de vista del Pueblo Mapuche, es advertido por Pu Mapuche en el espacio judicial, como prueba de que existe y ha existido, con la utilización de diversas estrategias diplomáticas esfuerzos para entablar una interlocución con el Estado, como lo señaló un Longko, en un intento de "conversar y ponerse de acuerdo".

Cuando estuvo el otro gobierno, conversamos con el ministro Lavin, que vino dos veces acá, tuvimos una conversación y sin ningún carabinero al lado, acá estuvimos, igual en el territorio igual vino, y nosotros tocamos ese tema, de la recuperación de tierras, que la tierra que nos tienen quitado que sean devueltos a los Mapuche, entonces es una conversación, y nos llevábamos bien, entonces eso es lo que queremos nosotros, sentarnos a conversar y a dialogar, entonces así conversamos nosotros como lonko, conversamos con las autoridades.

Pregunta abogado: ¿y en esas conversaciones qué han dicho las autoridades?

Dicen que vamos ver si ponerse de acuerdo, pero no se han puesto de acuerdo nunca, entonces se ponen sordo a veces, sordo o ciego, no nos escuchan, entonces nosotros queremos que seamos escuchados, eso necesitamos nosotros, que nos escuchen, que nos escuchen al pueblo Mapuche, eso es lo que necesitamos.

\section{Tensiones, equívocos, antagónismos e malentendidos desde una posición de la perspectiva Mapu}

El aumento de la criminalización a los procesos de retomada de tierras y las destrucciones que se hacen a $\mathrm{Pu}$ rewe, Nguillatuwe y sitios ceremoniales nos sitúa en lo señalado por DiGiminiani (2015) al proponer que "comprender la formación de la tierra requiere de una imaginación antropológica que reconozca el antagonismo conceptual de las geografías estatales e indígenas" (Di giminiani, 2015: 1) y ese antagonismo en el espacio judicial emerge como siendo un imperativo, cuando las causas que están siendo juzgadas están asociadas con un dicho de preso político Mapuche donde se asume desde diversos colectivos $P$ u Mapuche que no se está juzgando a una persona, sino a un pueblo, aunque en ese proceso surjan acusaciones de inautenticidad de las demandas Pu Mapuche, lo cual nos sitúa en lo que ha señalado también Di Giminiani (2013) "Cuando los sitios sagrados y sus usos son malinterpretados como inauténticos por funcionarios del Estado, ellos pueden últimamente ser usados para deslegitimar las demandas indígenas" (Di Giminiani, 2013: 528) y en el camino de deslegitimar esas demandas Pu Mapuche según también lo señalado por el autor, se camina en:

Una falla para reconocimiento de una diferencia radical en el entendimiento de sítios sagrados Mapuche por los actores del Estado. Al identificar estas características como símbolos empleados con fines políticos, los funcionários del Estado ignoran los princípios ontológicos que hacen de esos sítios sagrados en la sociedad Mapuche. Di Giminiani, 2013: 528)

En los Tribunales se señala que "En el mundo Mapuche existe una concepción de territorio que escapa o está muy lejos de lo que se llama o se conoce como la propiedad privada", por José Quidel como perito antropológico en un juicio, y continúa diciendo que:

Las personas somos una parte más de una cadena de vida animal, vegetal, animal, espiritual, cósmica, y obviamente también desde personas humanas, en ese ámbito, en esa concepción, hay una, un actor se funde, la connotación humana, con la connotación animal, con la connotación vegetal, por lo tanto los cerros pasan a ser seres vivos, los 
manantiales, los ríos, las aguas son seres vivos, además de eso, toda esta territorialidad, todo este cosmos, tiene una connotación que es inmaterial, que es la alienación espiritual, en este caso los Ngen que son los dueños del espacio, los manantiales, de los ríos de los cerros, de las cortezas, de las aguas, de los animales, de las aves.

La pericia antropológica realizada por José Quidel en el año 2015 y que sirvió como defensa de personas reivindicadas como Presos políticos Mapuche presenta y coloca en el espacio judicial y la jurisdicción del Estado nación una traducción pensada para que el tribunal entienda las relaciones tras específicas que se tejen en el ser Mapuche y que nuevamente nos llevan a reflexionar sobre el ixofillmogen como un concepto Mapuche que se refiere a la coexistencia de todas las formas de vida en y de los espacios.

Desde una perspectiva Mapu como espacio desde lo señalado por Quidel (2012) se nos lleva a plantear más a $P u$ Mapuche como personas o gente de los espacios y no como la traducción general de gente de la tierra, siendo que ejercicio de imaginación antropológica al que se refiere Di Giminiani (2015) pertinente para la geografía, se encuentra enriquecido, cuando situados en el espacio judicial Pu Mapuche enfrentan las tensiones propias del antagonismo conceptual, en tanto la tierra es vista como materialidad del territorio (Elden,2010) y queda expuesta a la "posibilidad de que los funcionarios estatales delimiten los reclamos de tierras de acuerdo con sus juicios sobre la importancia cultural de los territorios ancestrales y los sitios sagrados involucrados en disputas por la tierra" (Di Giminiani,2013:535)

Compartimos a continuación un aparte de la transcripción de una de las jornadas del juicio, donde por un lado, dentro de los muchos elementos que se pueden experimentar en el espacio judicial, nos encontramos con que hay evidentemente una tensión conceptual entre las geografías estatales y la geografía Mapuche, toda vez que lo que emerge constantemente es más allá que una representación que hacen $P u$ Mapuche del espacio geográfico, un reflejo de una experiencia de comunicación con ancestros (Goldman,1999) que remite a lo que está siendo el espacio geográfico $P u$ Mapuche, que se aleja de la producción social del espacio geográfico, para adentrarse en la coexistencia de seres que están y son de los espacios que se consideran como construídos (Quidel,2012) y compuestos a su vez por conexiones tras especificas donde el lawen no es visto solo como una "especie vegetal" o como "bosque", sino como un ser vivo.

$\mathrm{Al}$ entender el Estado las plantaciones de pinos y eucaliptos como bosque, entra en confrontación con las posturas y prácticas espaciales $P u$ Mapuche que se posicionan contra lo que afecta el ixofillmogen donde sitúan a las empresas forestales y las afectaciones que las mismas han traído para las prácticas $P u$ Mapuche de coexistir en los espacios. Lo anterior hace emerge en el espacio judicial las tensiones que se abren y que se presentan en relación a los métodos de medición y calculación del territorio que tiene el Estado nación, que se posicionan en el centro del debate.

Pegunta de abogado: pero el predio cómo se llama.

Bueno, es de Mininco, según ellos eso es de Mininco, pero resulta que son tierras de los indigenas, porque son tierras de nuestros antepasados y eso señores abogados nosotros lo vamos a luchar hasta las últimas consecuencias, hasta recuperar las miles de hectáreas que nos tienen usurpadas esas empresas

en la sala se oye un fuerte afafán

YAYAYAYAYAYYAYAYYAYAYAY

Por favor silencio en la sala (habla el juez) 
Ministerio Público: su señoría, no tengo ningún problema en que lo haga el público, pero no el imputado, él tiene que mantener respeto al tribunal y a los que estamos aquí, está sometido a la jurisdicción chilena, que se someta a la jurisdicción

se advierte al público que si no se mantiene el orden la sala podrá ser desalojada

Abogado de la defensa Mapuche: magistrado igual conviene hacer un alcance que dentro del propio convenio 169 si bien es cierto estamos en la jurisdicción del estado chileno, sin embargo, la propia jurisdicción de Chile reconoce el convenio 169

Juez: estamos hablando de una cuestión de respeto hacía el tribunal y hacia el testigo que está deponiendo

Abogado de defensa: si me permite hacer la alegación

Juez: el tribunal es el que está haciendo un llamado al orden. Continúe

Abogado de la defensa: Don Juan, ¿qué dignifica ese grito o el sonido que acaban de admitir los asistentes o el público en la sala?

Ministerio Público: objeción su señoría, es impertinente la pregunta

Abogado de la defensa: su señoría solicitaría que se pudiese fundamentar la objeción sin que se diga solo una palabra.

Ministerio Público: su señoría, el punto está claro de qué es lo que tiene que hacer, que un grito no es y no tiene nada que ver con lo que estamos escuchando en la declaración sumamente respetuosa del testigo y la pregunta no tiene ninguna relación.

Abogado de la defensa: en la medida en que los usos y costumbres del pueblo Mapuche en general, esto que vanamente le denomina como grito, esto hace parte de la cultura del pueblo Mapuche y todo esto se enmarca dentro de un proceso de reivindicación, recuperación territorial, creo que la pregunta es pertinente sobretodo en la teoría que ha dado la defensa

Luego de la intervención del abogado de la defensa Mapuche el juez y quienes le acompañan deliberan durante unos pocos minutos, finalmente el juez señala "el tribunal acoge la objeción, no hay lugar a la pregunta por impertinente, puede continuar.

La tensión anterior en un juicio contra miembros del pueblo Mapuche reivindicados como Presos políticos Mapuche pone de presente la emergencia de los sentidos y prácticas de ancestralidad en el espacio judicial donde el uso de la palabra por los que son llamados de "imputados" así como de los testigos de la defensa abre la posibilidad de lanzar y hacer circular un mensaje que al señalar el téstigo en frente a un tribunal en la jurisdicción del Estado chileno que "las miles de hectáreas que nos tienen robadas esas empresas las vamos a recuperar" lo dicho se presenta como subversivo y transgresor para el Estado nación, en tanto ese mensaje se hace público y circula como las motivaciones que hay por detrás de lo que el Estado y los medios de comunicación presentan como "conflicto Mapuche".

El trato de nación a nación que tuvo el pueblo Mapuche con la corona de España, en donde como lo afirman Correa y Mella (2009) se planteó una relación en condiciones de igualdad, en tanto fueron reconocidos como autoridades los Futal Longko y desde antes de la creación del Estado nación ya se reconoce a un pueblo que tiene un sistema socio político concreto como un pueblo con muchos pueblos, más cercano en el concepto de Futal Mapu que señala Quidel (2012) que no es Estado céntrico pero el mismo es válido en la medida que era y es practicado. Siguiendo la perspectiva anterior nos movemos con las provocaciones de los pensadores de derecho propio y sistemas jurídicos propios de Canadá, principalmente Napoleón (2009) cuando se refiere a las tradiciones legales indígenas. 
Los conceptos temporales que son presentados en el espacio judicial por Pu Mapuche como el concepto de Kuyfi siendo el tiempo de los ancestrales, que actúa en el presente Melin et al (2017) nos llevan a mirar este espacio como espacio de confrontación de tiempos históricos del Estado nación y las historiografías contrahegemónicas que traen y reivindican el habla de los ancestrales a partir de la cual re piensan los sentidos de la historia.

\section{Abogado: ¿por qué dice que hoy en día quieren la tierra, no tienen la tierra ustedes?}

Testigo Mapuche: Mire, yo quiero que escuchen todos los que están aquí presentes, hoy día ustedes lo saben, de que el Estado chileno y cuando llegaron los españoles, robó y nos dejaron sin tierra, a los primeros habitantes y los que vinieron detrás, vinieron a robarle a nuestros longko, a nuestros abuelos, a nuestros padres y hoy dia no tenemos tierra es por ello, cuando les digo que escuchen, a mi longko Juan Andrés Polma que fue gobernador antiguamente, él mandaba de mar a cordillera y colindaba con la novena, cuando llegaron los españoles, hoy día están las forestales, nuestra reducción nos queda chica, 10 hectáreas, cuando teníamos miles de mar a cordillera, como vuelvo a repetir, de Nahuelbuta, no estamos hablando de 500 ni 50 hectáreas, estamos hablando de 45000 hectáreas de mar a cordillera.

Las palabras anteriores fueron mencionadas por una autoridad socio política del pueblo Mapuche, un Longko, que reivindicaba el enunciado y experiencia transmitida por los ancestrales de que "vinieron a robarle a nuestros Lonkgo, a nuestros abuelos, a nuestros padres y hoy día no tenemos tierra es por ello" que está presente en la mayoría de procesos de $\mathrm{Pu}$ Mapuche que reivindican que lo que se dice de recuperación territorial está enmarcado dentro de un proceso de reconstrucción como pueblo nación, que envuelve una continuidad con las luchas de los ancestros Pu Mapuche.

En el mismo juicio el perito antropólogo Mapuche José Quidel amplió lo que podría estar siendo a lo que se refieren $P u$ Mapuche cuando hablan de recuperar, porque como al igual que el robo hecho a los ancestros $P u$ Mapuche que fue reivindicado por la declaración que compartimos anteriormente del Longko en el juicio, existen procesos, que enmarcados en el propósito que $P u$ Mapuche señalan de reconstrucción como pueblo nación, mediante el habitar espacios que han sido cultivados con eucalipto y pinos, o que están en manos de grandes terratenientes, reivindican las acciones de recuperación como imperativos dentro del proceso de reconstrucción como pueblo nación.

La forma socio política Mapuche, los Futal Mapu, Rewe,Lof,Lofche, impide que se hable de que existe una organización orgánica que pueda hablar y "representar" al pueblo Mapuche, en tanto estamos ante lógicas que no son Estato céntricas como hemos señalado anteriormente y que de por si dentro de las prácticas espaciales referidas a los Futal Mapu, entendidos también como identidades territoriales, nos confrontamos ante un pueblo con muchos pueblos como también fue señalado anteriormente.

Es persistente mencionar como lo señaló en el juicio José Quidel referente a la recuperación y como ha sido por su parte señalado por distintos investigadores como Foerster y Montesinos (1988) el histórico de unas prácticas y procesos organizativos que no se han movido única y exclusivamente en postulados autonómicos, pero que han mantenido los enunciados y prácticas con respecto al reclamo y demanda por recuperar el territorio ancestral Mapuche.

Se va a entender que lo que se busca es reconstruir un territorio, reconstruir un proceso que se ha perdido, recuperar lo que se ha perdido, recuperar una noción conceptual de un modelo de vida, que es a partir desde el contacto con la sociedad chilena, hasta en la colonia, a partir de la estructuración del Estado nacional, la relación de los pueblos indígenas con la sociedad chilena ha sido catastrófica, y el pueblo Mapuche ha ido perdiendo no solo el 
territorio, sino ha perdido la lengua, conocimiento, sino también identidad, debido a que ha sufrido transformaciones brutales, persecución en distintos momentos, en ese sentido este conocimientos han sido traspasados de generación en generación, desde las primeras organizaciones Mapuche a principios de 1900, desde Caupolicán, vienen apuntando a una reconstrucción y a una resistencia.

\section{Haciendo un zoom a Camilo Catrillanca Marin como hijo de un pueblo con muchos pueblos}

En la región de la Araucanía, provincia de Malleco, comuna de Ercilla, específicamente en lo que se conoce como el bajo Malleco, se encuentran procesos de $P u$ lof Mapuche, que han logrado mediante propuestas de lo que reivindican como control territorial y recuperación territorial que hoy hayan sido demarcadas hectáreas que estaban en manos de grandes terratenientes principalmente y estos llamados procesos de recuperación de tierras se encuentran en distintos puntos de lo que se reivindica como el Wallmapu, tanto en lo que se dice de Ngulumapu (hoy conocido como Chile) así como lo que se dice de Puelmapu (hoy conocido como Argentina).

Hay predios que emergen en la memoria oral de $P u$ Lof de esta área y conocida como Temucuicui (autónoma y tradicional), donde se encuentran los fundos alaska, la romana, en cuales hoy pu lof llevan a cabo una propuesta que enmarcan dentro de enunciados de autonomía y derecho a la autodeterminación. Implicando el predio conocido como la romana, donde el joven Mapuche Camilo Catrillanca se encontraba construyendo su vivienda el día 14 de noviembre del año 2018 antes de ser divulgada desde Temucuicui la noticia que estaba siendo ampliamente difundida informando que había sido asesinado Camilo Catrillanca.

El asesinato de Camilo sucedió mientras él se encontraba desarmado junto a un menor de edad Mapuche y se desplazaban en un tractor en el lof Temucuicui en el momento en que sintieron las balas que le dieron muerte a Camilo Catrillanca sin mediar ningún enfrentamiento. También en Ercilla fue encontrado muerto el día 31 de diciembre del 2018 el Lonkgo Juan de Dios Mendoza Lebu padre y tío de dos Pu Mapuche inmersos en procesos de recuperación, quienes fueron asesinados en extrañas circunstancias, sin que hasta el día de hoy se tenga claridad sobre los hechos. (Ref. Radio UdeChile).

El asesinato de Camilo Catrillanca se da a un año de que en medio de un proceso de recuperación del que $\mathrm{Pu}$ Mapuche reivindican como territorio ancestral, miembros de la policía militarizada de Argentina asesinaron a Rafael Nahuel en el área conocida como el lago Mascardi, en el parque Nahuel Huapi, reclamado por Pu Mapuche como territorio ancestral Mapuche, donde se hace necesario remitirse a la prima de Rafael Nahuel, considerada como la primera Machi (conocido en la literatura etnológica como chamán pero que en todo el documento referimos de Machi) que se "está levantando" después de la conocida como la conquista del desierto, es decir, la serie de operaciones militares llevadas a cabo, para adherir el territorio habitado por $P u$ Mapuche del Puelmapu, como se denominan Pu Mapuche que habitan en parte de lo que hoy conocemos como Argentina.

La Machi fue según versiones de $P u$ Mapuche, obligada a comer tierra, "te gusta la tierra?, pues come tierra" le habría dicho la policía, en medio del violento proceso de desalojo en donde resultó muerto Rafael Nahuel (Ref. Alonzo, 2017) justo el día en que era enterrado en su ciudad natal el joven apoyador Santiago Maldonado, quien se encontraba junto a otros miembros del lof wente winkul mapu en la región conocida como Chubut, manifestándose por la prisión del Longko Facundo Jones Huala, cuando fueron objeto de una violenta operación militar, en la cual desapareció Santiago Maldonado y fue encontrado muerto unos meses después, siendo señalando desde el pueblo Mapuche y sus principales autoridades que en todos los casos que han sido 
mencionados se trataba de la muestra y la prueba de cómo opera el terrorismo, pero esta vez sí, un tipo de terrorismo que Pu Mapuche califican como terrorismo de Estado.

La versión con respecto a lo que pasó el día 14 de noviembre con el asesinato del joven Camilo Catrillanca, siempre fue la misma desde los familiares y su Lof, así como las principales autoridades $P u$ Mapuche donde se convocaron distintos escenarios de encuentro llamados de Futa trawun y se emitieron comunicados que insistieron e insisten, en las demandas que $\mathrm{Pu}$ Mapuche sostienen al Estado nación, muchas de las cuales persisten desde su creación, esas demandas hoy son a saber: desmilitarización del Wallmapu, restitución del territorio, comisión de verdad y esclarecimiento histórico, a lo cual se suma la coyuntura de los intentos de modificación de la conocida como ley indígena que segundo Pu Mapuche desde los intereses del Estado nación se quieren entregar las pocas tierras reconocidas como indígenas hoy, al servicio de los dichos mercados de tierras y las especulaciones empresariales en distintos sectores.

\section{Geografías perspectivistas o apuntes para pensar una geografía vida- céntrica}

A los pocos días del asesinato de Camilo Catrillanca, dentro de las muchas muestras de rechazo a las acciones de los Estados nacionales y de apoyo a las demandas del pueblo Mapuche, fue hecho por un grupo de geógrafos y geógrafas que trabajan en el Wallmapu, un manifiesto que presentaron llamado "contra la geopolítica de la muerte, una geografía de la vida".

En el llamado se puso en evidencia, que el modelo extractivo que promueven los Estados nacionales: "Atenta contra el ixofillmongen, es decir, sobre todas las formas de vida sin excepción alguna. Ngen, leufu, lemu, uñum, wingkul, mallin, entre muchas otras entidades que entran en relación con la existencia Mapuche, hoy se encuentran amenazadas, generando violencia estructural, epistémica y ontológica. Afectando al $\mathrm{Az} \mathrm{Mapu,} \mathrm{orden} \mathrm{territorial} \mathrm{Mapuche,} \mathrm{se} \mathrm{afecta} \mathrm{la} \mathrm{existencia} \mathrm{de} \mathrm{nuestro} \mathrm{pueblo"}$ (Mansilla y Huiliñir Culio, 2018).

El llamado y urgencia de una geografía para la vida que se posiciona contra la geopolítica de la muerte, nos motiva a pensar y reflexionar sobre los trabajos $\mathrm{Pu}$ Mapuche que están tensionando a los debates sobre la producción social del espacio que en la geografía se ha inspirado profundamente en las propuestas de Henri Lefebvre pero que reivindican y posicionan una perspectiva Mapu (Melin y otros,2017;Quidel,2012) y sobretodo se refieren no a un proceso de producción del espacio y si a actos de construcción de la vida (Quidel,2012;Huaiquinao et al,2017).

A continuación, los mapas que se presentan se posicionan como contrarios al ordenamiento territorial y lógica cartográfica de los Estados nacionales que remiten al recorte y a las políticas de medición y calculación que le son propias a esos recortes. Los mapas hacen presente y remiten al territorio ancestral Mapuche visto desde una lógica cartográfica Pu Mapuche sin divisiones y retazos y orientado hacia el este, como es el sistema de geo - posicionamiento Mapuche (Millaman,2006;Melin et al, 2017) así mismo como los dos mapas realizados por Millaman (2006) donde se reafirma la continuidad tras andina, ha sido difundido un mapa compartido desde los procesos organizativos del queserefiere como el futalwillimapu o los grandes espacios territoriales del sur que utilizaron y utilizan este mapa dentro de las estrategias emprendidas para enfrentar las amenazas por la pretensión de construcción de hidroeléctricas y grandes emprendimientos, lo cual impulsó la circulación de este mapa que se posiciona en la lógica de la orientación y geoposicionamiento Pu Mapuche. 


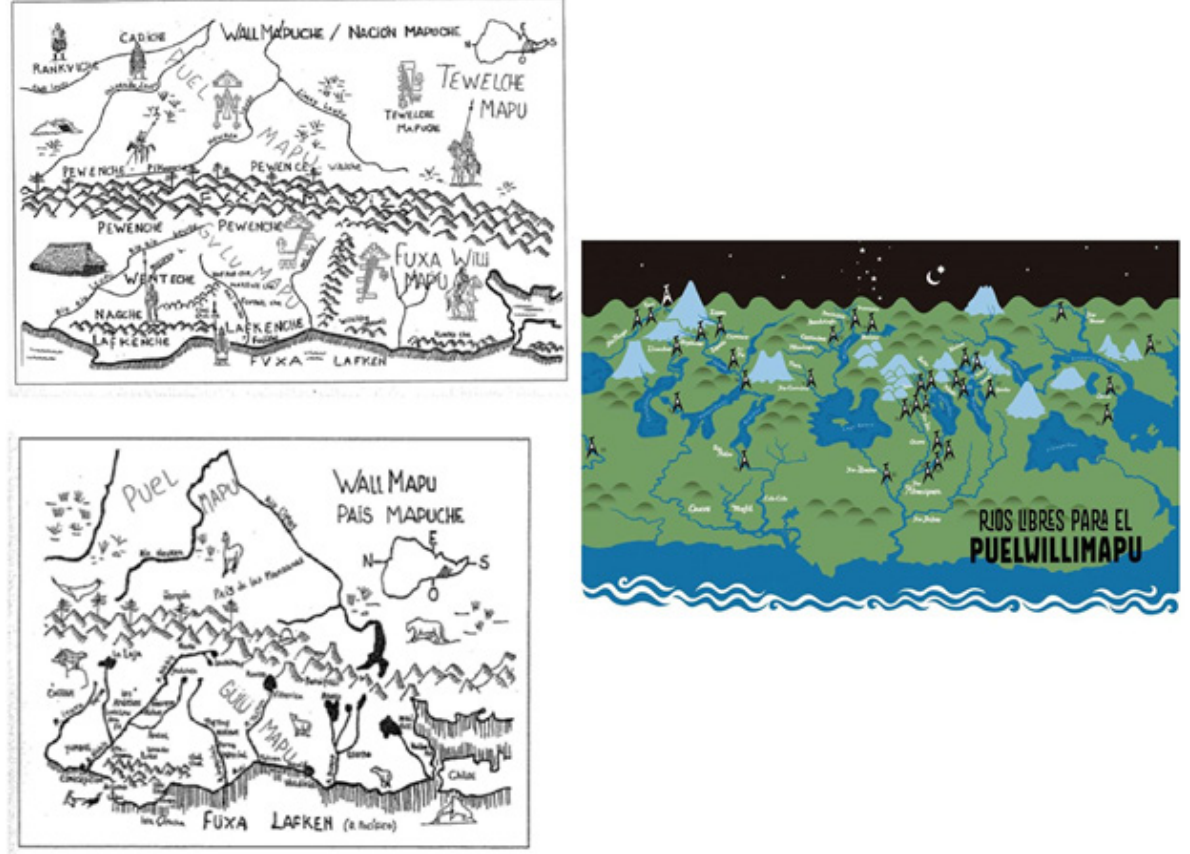

Figura 1. Mapas circulados por Pu Mapuche con orientación este.

Fuente: Mariman (2006: 60, 77) y FutalWilliMapu-Todos los ríos libres.

La orientación este desde el kimon y el rakizvan y los debates que se adentran desde $\mathrm{Pu}$ Mapuche en los conceptos de coexistencia de diferentes formas de vida y de construcción de los espacios (Ref. Quidel, 2012; Melin et al., 2017) se presentan como imperativos de las prácticas espaciales $\mathrm{Pu}$ Mapuche que se posicionan a su vez desplazado a la especie humana como privilegiada portadora de la condición de humanidad y vivencian en la práctica la geografía vida-céntrica (Quidel, 2018) que ya nunca más posiciona a la geografía, como la ciencia del espacio del hombre, sino como una ontología o coexistencia de los seres de y en los espacios (Ref. Quidel, 2016).

Desde un punto de vista Mapuche el ordenamiento territorial ancestral fue en definitiva golpeado y apagado con la creación del Estado nación y la imposición de un régimen cartográfico del recorte ajeno a $\mathrm{Pu}$ Mapuche. Los procesos de mapeo han incluido rizomáticamente toda una serie de actores Mapuche y no Mapuche que han dado una vida jurídica a estos procesos de mapeamento mediante el acompañamiento de causas judiciales. Los procesos de mapeo remiten a una demanda identificada desde las prácticas y enunciados espaciales Pu Mapuche como lo señalado por Melin et al. (2017) en el denominado Atlas Mapuche, que es un proceso de mapeamento inédito que envuelve a distintos $P u$ Lof, que siendo llamados por el Estado nación de "comunidades" hoy se encuentran en un proceso de hacer visibles a través de los mapas los límites en una lógica Mapuche, una lógica de lo que llaman de los Pu Lof como proceso intrínseco a la reconstrucción como pueblo nación que se posiciona también desde el recuperar las formas propias de nombrar.

En la vía de la reconstrucción de las demandas territoriales $P u$ Mapuche se han llevado a cabo procesos y ejercicios de contra - cartografía dentro de los cuales, uno de los pioneros es el realizado por Hirt (2012) cuyo ejercicio constituyó un campo de experimentación, que dejó desde una interlocución con el kimon (conocimiento) y el rakizvan (pensamiento) Mapuche importantes reflexiones para la geografía que se dice moderna en aras de abrir un camino a la descolonización, o en la reflexión de una ciencia geográfica más allá de lo humano, lo anglo y norteamericano como han hecho eco desde la geografía autoras como Panelli (2008). 
Schavelzon (2016) reflexiona y propone el concepto de guerras ontológicas que llevamos al entender el mapa como una posibilidad de hacer visible en el momento en que se vale de las herramientas que están disponibles para hacer mapeamentos. La apropiación metodológica también se ve afectada por la perspectiva Mapu porque la perspectiva Mapu trae no un decalque o una copia de los mapas y del territorio del Estado sino que teje tiempos de los ancestrales, límites, prácticas y enunciados atravesados por los puntos de vista de diferentes especies, lo cual es intrínseco al concepto de coexistencia de todas las formas de vida en y de los espacios como el ixofillmogen.

Di Giminiani (2013) explora los equívocos relacionados a la tierra y lo sagrado, en el marco de procesos de reclamación de tierras en donde a su vez se han dado procesos institucionales de reclamo, que han insertado las demandas en el espacio judicial, entrando en el campo de disputas donde los equívocos florecen y que son presentados por el autor, por medio de los juicios de inautenticidad que hacen actores de los Estados nación para deslegitimar las demandas Pu Mapuche.

Di Giminiani sitúa su inquietud en los equívocos que surgen en la relación dicha de intercultural:

Las razones por las que los sitios sagrados envueltos en las negociaciones de tierras pueden parecer tan diferentes a los reclamantes indígenas y los funcionarios estatales se desarrollan mejor si exploramos la posibilidad de que ambas partes puedan emplear los mismos conceptos para referirse a mundos radicalmente diferentes. Dos nociones en particular, "Mapuche" y "sagrado", están sujetas a interpretaciones divergentes. (DiGiminiani, 2013: 535)

A pesar de lo anterior la reflexión y práctica sobre una cartografía propiamente Mapuche viene con la realización y publicación del atlas Mapuche realizado por la organización socio - política Mapuche Alianza Territorial Mapuche - ATM en el año 2017, en cuyo prólogo Carlos Walter Porto Gonçalves señala que:

El Atlas que aquí se muestra no solo es situado en una geografía determinada de los MapuChe, es también fruto de un conocimiento que viene de las experiencias de lucha, sea con/contra la invasión de hidroeléctricas, sea por la recuperación de sus tierras - territorios. Así se demuestra como el conflicto es el locus privilegiado del punto de vista epistemológico al indicarnos que en una determinada situación como mínimo tenemos dos visiones acerca de lo que está en cuestión. De esta forma, este atlas surge del conocimiento elaborado a partir de las luchas MapuChe rearmando sus triunfos no tan solo en el plano material, sino que también los que han resultado de sus victorias epistémicas, que aquí se revelan a modo de Atlas. (Melin et al., 2017: 6).

Las victorias epistémicas a las que se refiere Porto Gonçalves, podrían ser vistas también como victorias ontológicas en tanto presentan relación con el quiebre ontológico al que se refiere Quidel (2016) cuando habla de la coexistencia de las diferentes y distintas formas de vida presente en la noción vidacéntrica Mapuche donde específicamente Quidel (2016) se refiere que "Desde el mapuche rakizuam, es la idea de que kom mapu ta mogeley, xür mogeleyiñ mapu iñnchin, mapu ñi zuam mogeleyiñ. Toda los espacios son seres vivos, espacios y nosotros los humanos vivimos juntos, gracias a estos espacios nosotros podemos estar vivos" (Quidel, 2016: 718) siendo que lo anterior conecta a Quidel (2016) con los debates del Atlas Mapuche realizado por la ATM en el año 2017.

Por otra parte el Atlas Mapuche (Melin et al., 2017) hace visibles críticas a definiciones que se han hecho a conceptos Mapuche y que desde la perspectiva Mapu que los autores defienden se presentan como siendo equívocos, en tanto las traducciones que se hacen de naturaleza y de biodiversidad impiden alejarse de las particiones ontológicas de naturaleza y cultura que cuestan a nuestra moderna ontología 
multiculturalista y uninaturalista como señala Viveiros De Castro [2009] (2018), esas particiones ontológicas de naturaleza y cultura propias del pensamiento euro américano no tienen lugar en el concepto Mapuche de Ixofillmogen como coexistencia de todas las formas de vida.

Lo que presentan Melin et al. (2017) y Quidel (2012; 2016) son las bases para hablar de una geografía de la vida, pensando su objeto desde un principio vidacéntrico:

Expresiones como IxoFillMogen (Itro llmo-gen) o FillKeMogen, a través del concepto de mogen ponen de manifiesto la noción de vida en su más amplio sentido y formas en todas las dimensiones del mapu. Y mediante la anteposición de ixo-ll se da cuenta del sentido de pluralidad en términos absolutos (ixo - como lo máximo de totalidad, ll-de diversidad). De esta forma, el concepto aglutinado en la expresión IxoFillMongen da cuenta de todas las formas de vida sin excepción. Entonces, Ixo llmo- gen viene a explicitar la existencia de la vida y sus distintas formas en cada una de las dimensiones del mapu (wenumapu, nagmapu y miñchemapu) (Melin et al., 2017: 20)

\section{Nuestro norte es el este}

La publicación del mapa que presenta una continuidad trasandina que es reconstruido por Mariman et al (2006) se presenta como una respuesta concreta, sobre una demanda territorial que se extiende en el tiempo por más de 130 años desde que se crea el Estado nación. La subversión del sistema de posicionamiento geográfico como orientado hacia el norte y desde la perspectiva Mapu retoma el este permite evidenciar con la forma en la cual se presentan los mapas, la retomada de la perspectiva Mapu desde una visión que se reivindica de ancestral del meli wixam mapu que está presente en el mapa de Mariman et al (2006) y que viene siendo retomada en mapas que han sido utilizados en el marco de conflictos con proyectos hidroeléctricos como puede verse en la cartografía que ha difundido el proceso de defensa del río pilmaiquén compartido anteriormente (Ref. Todos los ríos libres 2014).

Melin et al. (2015) trabajó sobre el Az mapu enmarcando este concepto como parte fundamental y central dentro de lo que sería el ordenamiento jurídico propio del pueblo Mapuche, parte de la tradición legal Mapuche (Napoleon,2013) que encontraría en este concepto una serie de normativas que relacionan y regulan a los humanos y no humanos que coexisten en los espacios territoriales.

Cuando se huye de la representación para verlo como prácticas espaciales concretas que delimitan y crean fronteras cuyos trazados ancestrales hoy son defendidos por $\mathrm{Pu}$ Mapuche que se reivindican en el marco de un proceso de reconstrucción como pueblo, se opera en otra vía o el espacio está siendo otro porque se quieren retomar los trazos que fueron estipulados en múltiples acuerdos diplomáticos con la corona española, los cuales fueron conocidos como parlamentos (Zavala, 2008; Melin et al., 2017). En el presente se reivindican desde $\mathrm{Pu}$ Mapuche las acciones que hoy deben ser retomadas más allá de verlas como si fuesen dirigidas solo a documentos coloniales como si los mismos estuvieran congelados en el tiempo de la historia sin ningún potencial de ser usados en las demandas presentes de reconstrucción como pueblo nación.

Dentro de la narrativa historiográfica, desde el punto de vista del pueblo Mapuche (reflejado por ejemplo en los trabajos de la Comunidad de Historia Mapuche) hay en la historia reciente y en los sucesos que tienen protagonismo en la memoria dos grandes momentos que marcan de forma significativa lo que es el territorio Mapuche en términos de sus fronteras, límites y divisiones y lo que eso relaciona; el primero de ellos es el contacto con la empresa colonial en el proceso de expansión colonial y el otro es la creación de los Estados nacionales de Chile y de Argentina. 
Con respecto al primero, mediante prácticas de auto defensa desde $\mathrm{Pu}$ Mapuche, se logró mantener un proceso de autonomía como pocos pueblos originarios durante el proceso de expansión colonial tal como ha sido documentado. Estos acuerdos diplomáticos fueron conocidos como parlamentos que fueron realizados entre el pueblo Mapuche y la corona española en su momento con las garantías de las misiones jesuitas.

Por lo anterior es de vital importancia a partir del reconocimiento de que más allá que el parlamento haya sido asociado en la bibliografía como una estrategia de dominación española, así como los Parlamentos se encuadran en una práctica de realización de este tipo de tratados como acuerdos de paz durante el proceso de expansión colonial, concordamos con Zavala (2008) que refuerza la idea que reconoce y sitúa el parlamento y señala sobre el mismo que:

A pesar de la riqueza de esta institución, los historiadores sólo han destacado su aspecto formal, es decir, en cuanto instrumento político-jurídico al servicio de los españoles. En esta óptica histórica, el Parlamento sería una institución española aplicada a una situación particular. Para nosotros, por el contrario, el Parlamento es una institución hibrida y tras-cultural. En todo caso, no es el fruto de la imposición española sino el resultado de un compromiso cultural establecido entre dos actores étnicamente distintos. Se trata sin duda de un instrumento de contacto utilizado por los españoles; pero también, de un instrumento utilizado por los mapuches para entablar relaciones con los españoles según sus propios criterios. Se puede ir aun más lejos y decir que, en cierto sentido, los españoles cayeron en la trampa de las formas de negociación indígenas puesto que, incapaces de imponerse por la fuerza, no les quedó otra solución que aceptar, 'protegidos' por el término 'Parlamento', un tipo de encuentro ritual que los mapuches practicaban mucho antes de la llegada de los españoles y que estos calificaron despectivamente de 'borracheras'. (Zavala, 2008: 160)

Más allá del Parlamento ser considerado desde una perspectiva de ser híbrido y transcultural, incluso investigadores Pu Mapuche y otros como Contreras (2008),Melin et al. (2017) son enfáticos en hablar que el parlamento fue y es una institución de origen Mapuche y lo que fue encajado por los españoles como Parlamento, fue una institución de origen Mapuche a la cual Pu Mapuche se referían como Koyang. "No sé si tienes idea de lo que es un parlamento en tierra de cristianos; y digo en tierra de cristianos, porque en tierra de indios el ritual es diferente. Un parlamento es una conferencia diplomática". (Mansilla, 1966, p.72 en Contreras-Painemal, 2008: 5). Con lo anterior hacemos énfasis en lo señalado por Zavala (2008) y Contreras-Painemal (2008) y que traen para el debate con respecto a que: "Los parlamentos o koyang no son de origen hispano sino mapuche, lo cual ubica estas ceremonias como una de las adquisiciones que habrían hecho los españoles de los mapuches" (Contreras-Painemal, 2008: 6)

\section{Memoria viva del despojo}

El despojo al cual se refieren $P u$ Mapuche si bien es cierto encuentra resonancia en los postulados que se han realizado en la geografía crítica radical de acumulación por desposesión (Harvey,2004) lo que encontramos particularmente en el acto de realización del juicio cuando se trata de alguien reivindicado como Preso Político Mapuche es que son puestos en tensión innumerables factores que hablan más allá $\square$ de las ya sabidas y documentadas violaciones a los derechos humanos y al derecho internacional humanitario como también ha sido señalado por Le Bonniec (2018) de un escenario donde se ponen a prueba elementos que hacen parte de Pu Mapuche y donde se tiene que demostrar que se es Mapuche, que es una demanda territorial y por sobretodo que no se es un "terrorista", "delincuente".

Uno de los Pu Mapuche que estaba siendo juzgado, hizo un comunicado y lo entregó para ser difundido en medios libres y alternativos y en el mismo él hacía énfasis 
en que la importancia de ese juicio radicaba en que al juzgar por hurto de madera, se estaba atacando la estrategia de lo que llaman la recuperación productiva, que se presenta como el aprovechamiento de las maderas de pinos y eucaliptos, que están al interior de los fundos en manos de empresas forestales y que son a su vez reivindicados en el marco de la demanda territorial más amplia del pueblo Mapuche como siendo territorio ancestral Mapuche. Como fue señalado por un Mapuche que estaba siendo juzgado:

Hoy nuevamente las reducciones Mapuche quienes defienden y luchan por recuperar el territorio usurpado que hoy se encuentran ocupados por los grandes empresas forestales, latifundistas e hidroeléctrica, nos encontramos ante un nuevo proceso judicial, es por ello que se hace necesario la presencia y el apoyo en todas las comunidades del territorio lafkenche, sus dirigentes principalmente, porque, lo que se pretende en tribunales es criminalizar la justa demanda, reivindicación y el trabajo productivo que se está $\square$ llevando adelante en las comunidades del sector principalmente, pero sabemos que esto se está $\square$ desarrollando en muchas comunidades desde Arauco hasta Coi coi, por lo que es muy importante el precedente que se genera tanto en términos judiciales y políticos, puesto que el trabajo productivo que se realiza en estas recuperaciones es un hecho que no se puede negar pues viene a mitigar el estado de pobreza de las familias Mapuche, esta es la realidad de las comunidades Mapuche de hoy. En estos días se presentan en tribunales como testigos nuestras autoridades ancestrales, nuestros longko, nuestra machi, nuestros wonen y werken, debemos acompañarlos, no dejarlos solos pues son nuestras autoridades que, en estas instancias difíciles, ellos nos representan y nos defienden a todos nosotros, y a toda nuestra Nación.

Por su parte la defensa estaba muy preocupada con hacer ver que hay otros significados en juego y que tienen que ver con cómo se entiende el territorio, como lo señalado por José Quidel en la realización de su peritaje antropológico así también como fue señalado por uno de los Pu Mapuche que estaba siendo juzgado que llevó su intervención a que el eucalipto y el pino al no ser nativos pueden ser aprovechados y cortados.

Es decir que desde miradas $\mathrm{Pu}$ Mapuche cortar y aprovechar pinos y eucaliptos no afecta el ixofillmogen porque la misma retirada del pino y del eucalipto es lo que va a hacer rebrotar la vida: "La concepción de territorio Mapuche tiene que ver con elementos vivos, la concepción de movimiento, que nosotros, personas que también no hay una visión antropocéntrica del sujeto, sino que hay una visión de vida, integral" señalaba José Quidel ante el Tribunal.

Quienes estaban siendo juzgados en ese momento, tenían una particularidad y tiene que ver con que eran $\mathrm{Pu}$ Kvriche, es decir, asistentes de Machi, lo cual, por las declaraciones que fueron dadas en el ese juicio hacen que las relaciones espaciales que ellos como Kvriche establecen no sean regidas por el ordenamiento territorial y las fronteras impuestas por el Estado nación, por lo cual ejercen su trabajo en donde se encuentren $P u$ Machi a quien acompañan al ejercer el rol de Kvriche y pueden actuar y son importantes para cualquier miembro del pueblo Mapuche independientemente de dónde el mismo se encuentre, así como fue señalado por un testigo de la defensa Mapuche: "Él siempre ha andado con la Machi porque la Machi tiene un don que Dios le dio y él anda de Kvriche y cuando la Machi tiene un sueño, que le da el espíritu el sabe buscar remedio por los cerros porque el lawen que nosotros decimos es un remedio y él anda buscando remedios para poder llevarle a la Machi".

Aunque la lógica cartográfica del Estado nación insista en el recorte y como lo afirman los trabajos de Correa y Mella (2009), Marimán et al (2006), insista en desconocer las fronteras, líneas, divisiones y sobretodo la lógica cartográfica ancestral lo que sucede hoy con los múltiples procesos que son llamados de recuperaciones de tierras y que 
se enmarcan dentro de lo que se llama reconstrucción como pueblo nación, nos sitúa y nos hace volver nuevamente a lo dicho anteriormente de que las geografías $P u$ Mapuche más que representación son prácticas espaciales concretas que hoy a partir de la reivindicación de trazados ancestrales reconocidos en acuerdos sustenta por ejemplo las recuperaciones de tierras que están concentradas en distintos puntos del Wallmapu y toda esa concentración de histórico de despojo emerge en el espacio judicial como teniendo agencia en el presente:

Una serie de espacios territoriales que son denunciados por las memorias del Ministerio de Tierras como unas formas engañosas de hacerse a las tierras a través por ejemplo de préstamos, de hipotecas, de embargos, de formas de pago absolutamente impagables, hay que entender que estamos hablando, el Mapuche que aprende a hablar castellano y que son, eso dicen en la memoria del Ministerio de Tierras no lo digo yo, sin embargo este gran espacio territorial que queda fuera, es demandado y forma parte incluso en la memoria histórica en algo que no es tan lejano, estamos tomando en cuenta que a lo que se le reconoce a los Mapuche en esos momentos es lo que tienen cercado y lo que tienen en las rukas, dejan afuera el gran espacio territorial que formaban los cerros, que formaban las aguas y todos los ríos

Las múltiples acciones que según $P u$ Mapuche han configurado el despojo territorial, afectan las prácticas espaciales toda vez que afectan el principio de coexistencia de las distintas y diferentes formas de vida al no permitir el crecimiento de plantas y seres de la especie dicha de vegetal que guardan especial significado en las prácticas cotidianas de $\mathrm{Pu}$ Mapuche.

Dentro de esas prácticas cotidianas que se ven afectadas está la elaboración de distintas piezas de uso diario en base al vegetal conocido como ñocha que entre otras también se usa para la elaboración de techado de rucas (casa), así como para distintos utensilios de diversos usos cotidianos y decorativos. En el juicio fue señalado lo siguiente:

El problema es que la ñocha pasa a ser en las propias plantaciones forestales, pasa a ser parte del solo bosque que le llaman en este caso las forestales, sin embargo, al momento de explotar los bosques, porque la nocha igual crece un tiempo, al momento de cortar los pinos y eucaliptos, cada vez que se hace una nacha, tanto la nocha, el maqui que sigue creciendo insistentemente en estos bosques, una vez que se explota se extrae de raiz, porque lo que hace el tronco es arrancar esa planta, por lo tanto muere la ñocha y por eso no queda ñocha.

Es así como entendemos que contra una lógica cartográfica del recorte se presenta una cosmo-práctica espacial del ixofillmongen donde las fronteras y delimitaciones que fueron hechas por los ancestros $\mathrm{Pu}$ Mapuche hacen presentar hoy el hecho de retomar y recuperar como una forma de liberar y de hacer volver a $P u$ newen que según $P u$ Mapuche son afectados de los lugares por el accionar de las empresas forestales en tanto la monocultura atenta contra un imperativo de Mapuche que es la coexistencia de distintas y diferentes formas de vida y esa práctica espacial que se ve afectada hace emerger las lecturas propias en el espacio judicial en torno al cómo se han instalado las políticas públicas, específicamente aquellas que han fomentado la monocultura de pinos y eucaliptos en lo que $\mathrm{Pu}$ Mapuche reclaman como territorio ancestral Mapuche:

Los Mapuche, nosotros nuestro newen, siempre lo hemos visto desde el ámbito espiritual, la conexión con la tierra, lo importante que tiene que tener, todos los elementos que la tierra tiene como los bosques, las aguas, las plantas, sin embargo, lo que hizo el decreto ley 701 de fomento forestal en el periodo de la dictadura militar, fue promover las plantaciones forestales en los distintos territorios y fijese usted que no fue en los grandes fundos donde tienen las plantaciones de viñas. Fue precisamente en los territorios Mapuche donde se fue implementando esto. Pero cuál fue la dinámica, cuál fue el argumento. De hecho hay una empresa que dice bosques para Chile, entonces se les pagaba, por poner una planta se 
les pagaba, eso se llamaba, se pagaba por poner la planta en la tierra, se pagaba porque esa planta pudiera aprender, significa que esa planta poder generar vida por ahí, se pagaba por poda y levante cuando ya empezaba a crecer la planta había que podar y eso le pagaban a la gente, a la empresa en este caso, o a las personas que plantaron, luego venía un primer saque de desechos y también se pagaba y se ponía mano de obra del propio gobierno, luego venía el primer relevo comercial y también se pagaba, finalmente fue un negocio redondo lo que hoy en dia han obtenido las empresas forestales a costa de la pobreza de nuestra gente, entonces cuando usted me pregunta es porque aquí hay una responsabilidad del Estado a través del decreto ley que dice que para poder generar recursos hay que plantar, y resulta que hoy día a pesar de haber pasado tantos años y vuelta a la democracia, hoy día se sigue plantando y este decreto ley sigue vigente.

El decreto ley 701 de fomento forestal al cual se refiere el testigo Mapuche y que se configura como un instrumento legal que permite ejercer un despojo, que no es un despojo que opera por lo menos en el ámbito solo de la desposesión a la cual se refiere Harvey (2004) y si como lo referido por Nahuelpan (2013) e Pairican (2014) opera en el ámbito de lo cotidiano, pero no cualquier cotidiano sino el cotidiano al que refieren $\mathrm{Pu}$ Mapuche como un despojo espiritual, despojo del Newen como lo relatado por el testigo anterior. La afectación es multidimensional, en tanto multidimensional se mira el Pueblo Mapuche (Quidel,2012) y afecta esferas sutiles que atraviesan cuerpos y prácticas Pu Mapuche, como otro testigo afirma:

Mire para mi debe ser porque realmente hoy en día el pueblo Mapuche quiere su tierra y a la vez hoy en dia las Machi no tienen lawenes porque hoy en dia hay médicos que tratan las enfermedades, el médico no le atina al remedio y para eso son las machi, longko,entonces la machi va a buscar el remedio a la cordillera, quiero que me escuche de por qué hoy día el pueblo Mapuche necesita sus cordillera, ya, porque hay antiguamente se iban a sacar los remedios, los lawenes que solemos decir como lengua Mapuche, los lawenes cuáles son? los lawenes son los remedios, que se hacen remedios y el enfermo alivie con eso, el remedio lo da la machi, digamos la tierra, por qué queremos los saltos, por qué queremos los tren tren porque antiguamente ahi donde estaban los longko, no solamente los longko, porque hay está la sabiduria del pueblo Mapuche, los saltos, nuestros abuelos, nuestros padres cuando no llovía nos llevaban a esos saltos a hacer llover, hoy en día por eso es que el pueblo Mapuche necesita de los llai llai que son los saltos, y en los cerros tenemos saltos, para hacer llover, que nos escuche y llueva, que han pasado los años y fueron como tres o cuatro que no llovió, entonces para eso es que necesitamos los saltos, para eso el pueblo Mapuche quiere su cordillera y quiere su salto.

\section{Los actos de construcción de los espacios}

Con todo lo anterior, lo primero a tratar es el equívoco (Viveiros,2004) en relación a que el espacio geográfico, lejos de pensarse desde $P u$ Mapuche como producido, es construído y así emerge desde $P u$ Mapuche que están escribiendo en interlocución con la antropología y otras áreas, sobre el espacio geográfico (Ref.Quidel,2012). La definición de espacio hecha por Quidel (2012) desde o Kimvn (conhecimento) Mapuche se hace presente señalando actos de construcción de la vida cósmica, precisamente que

Desde la perspectiva Mapuche, no podemos hablar tanto de creación, pero de establecimiento, formación, ordenamiento y control, que dan origen por su vez a una constante transformación que sería la vida. En ese sentido encontramos básicamente cuatro actos de construcción de la vida cósmica, el primero de ellos puede ser elün (establecer), wizün (formar), azkunun (ordenar transformación) e günen (control)". (Quidel, 2012, p. 81).

El autor se refiere también a los dueños controladores Geh señalando que: 
Las diferentes especies, establecidas, moldeadas, ordenadas y controladas por las fuerzas cósmicas, manifiestas como familias, establecen otros seres más próximos que son una especie de duenos (geh) de las diferentes formas de vida existentes en las dimensiones del universo (Wallmapu). La estructura es similar a una orden anterior. Para ejemplificar, se muestra un esquema basado en cuatro especies de vida, pensando en la dimensión terrena (mapu), en la especie animal (kujiñ), agua, vida líquida (ko), cerros (wingkul), pudiendo existir um dueno controlador (geh) para cada vida (mogen) (Quidel, 2012: 84)

En la interlocución con las prácticas espaciales $P u$ Mapuche se hace necesario retomar los conceptos Pu Mapuche que son senalados desde la perspectiva Mapu, dentro de los cuales varios son: "Ad mapu, Meli wixam mapu, xalüwen, ixofillmogen, rakizuan, zugu, xawün, xawümen, wirin/wieintukun, mapuche kimun,kulxug, kimche, inawmen, inaramtun, futal mapu, chillka/chillkantukun, antü, aylla rewe" (Melin et al,2017) en la propuesta de llevar a serio los conceptos $\mathrm{Pu}$ Mapuche desde esa perspectiva Mapu, como siendo uno de los vehículos de comunicación de modos otros de construir mundos (Albert y Kopenawa,2015) que se alejan del imperativo de los flujos capitalísticos del neo extractivismo que miran aquello que $\mathrm{Pu}$ Mapuche mira como un 'bien común' como equívoco de 'recurso' o que mira un proceso de producción del espacio, mientras que desde el rakizuan (pensamiento) Mapuche, según Quidel (2012) ese es un proceso de actos de construcción de espacios (Quidel, 2012:81)

Lo anterior está en conexión con lo retomado por Becerra y Llanquinao cuando se refieren a que el lenguaje del poder realiza una "Cosificación de los ríos, de los bordes marinos, los bosques, las montañas, conceptualizándolos como recursos y manejándolos como activos" (2017:9) y donde ese proceso que hoy se presenta como de reconstrucción como pueblo nación, está "retomando prácticas de los antiguos a través de los sueños" (2017:11) y se va reconstruyendo a su vez la toponimia ancestral o üy Мари (2017:11), presentando "espacios parlantes en tiempos particulares" (2017:11) donde como lo señalado por los autores, "los no humanos se expresan" (2017:33-34) a lo cual agregamos que los humanos ancestrales también, que emergen referidos por Pu Mapuche como Pu Longko.

El enunciado de la "Mapu siente y oye" que se traduce generalmente como la "tierra siente y oye", dicho en el juicio por una Machi que fue testigo, se repite a lo largo de los pueblos dichos de Ameríndios. Particularmente en el caso Mapuche, Mapu cuando es traducida de tierra, no es un énfasis en la dimensión material, no es la materialidad del territorio desde la perspectiva Mapu.

MAPU adquiere una dimensión tan amplia que las ideas de "tierra", "territorio" y "territorialidad" quedan en ella incluidas en la medida que dan cuenta de una vinculación humana con el entorno, por lo que los procesos de reconstrucción de los lof o los fütalmapu pasan -necesariamente- por identificar los "territorios ancestrales" que mayoritariamente aparecen interferidos y reducidos por presencia de "tierras wigka", mediante la constitución de la propiedad privada a través de fundos, forestales, parques nacionales, actividades extractivas de recursos naturales y la propias ciudades asentadas en su interior, entre otras formas de transgresión territorial. (Melin et al,2017: 14).

Em Mapuzugun que es la lengua Mapuche referirse a la dimensión territorial, tiene relación con cuando Pu Mapuche se refieren a Mapu, Mapu es un concepto que no cabe en las elaboraciones de la geografía moderna, porque en la Mapu y en ese concepto de espacio, están en pie de igualdad humanos, animales, vegetales, hongos, humanos ancestrales, como lo vemos en los trabajos de la Alianza Territorial Mapuche (Melin et al, 2017).

MAPU adquiere entonces una multiplicidad de connotaciones de acuerdo al contexto o a la finalidad con la que se presenta en el discurso y que van, desde la idea de 
"tierra" como predio hasta la noción de país, incluso, a la propia lengua mapuche, ya que tiene que ver con "la lengua que hablan las personas que habitan el mapu". Ello debe ser entendido dentro de la característica polisintética del mapuzugun, que da cuenta de las variadas acepciones de una palabra según el contexto o sentido de uso. Tal es, pues, el nivel de importancia de la expresión mapu, que forma parte de la adscrip- ción identitaria de la persona (mapuche ta iñ- che), como también del autorreconocimiento colectivo como pueblo o nación mapuche por parte de sus integrantes (taiñmapuchegen). (Melin et al,2017:13)

Al ser entendida como la condición del territorio, la territorialidad en el contexto Mapuche, adquiere importantes metamorfosis generadas por el equívoco que hay en el entendido de que el territorio, al ser un concepto colonial y al no encontrarse para el Estado definido lo que es el territorio, pero si como el mismo se organiza y administra (Calavia,2015), se posiciona como un objeto de disputa y debate constante que en la relación intercultural y los juegos de lenguaje que la misma acarrea, hay conceptos que se traducen en los términos de los enunciados espaciales de espacio geográfico, tierra, territorio y territorialidad, pero que los mismos de por sí están lejos de las distribuciones ontológicas que están intrínsecas al pensamiento occidental en torno a la naturaleza y la cultura como se encuentra en el trabajo de la Alianza Territorial Mapuche (Melin et al, 2017).

Tanto es así que desde la perspectiva Mapu (Quidel,2012;Pichinao,2012;Melin et al, 2017;Becerra et al, 2017) se alerta sobre los equívocos fundamentales a los que remite la traducción que se ha hecho costumbre del concepto Mapuche dixofillmogen que es traducido de biodiversidad, de naturaleza, pero que esos conceptos propios del pensamiento euro americano llevan intrínsecas las distribuciones de naturaleza y cultura. Las mismas categorías y conceptos que se presentan como equívocos, creados por la antropología en la equivocidad que acarrea la relación intercultural, como bien lo ha señalado Roy Wagner y Eduardo Viveiros De Castro.

La práctica y entendimiento vidacéntrico que se encuentra intrínseco al hablar de todas las formas de vida como la traducción que hacen (Melin et al,2017;Mansilla y Melin,2018), donde todo está vivo, hasta las piedras y donde los que occidente llama de muertos son humanos ancestrales - Pu Longko que continúan en comunicación y construyendo junto política, nos convida a pensar la ejercicios más de cuño cosmopolítico (Stengers,2018), porque están trayendo al cosmos a la política y están haciendo irrumpir a Mapu y a Pu Lonko en la política.

Al no ser una teoría en el sentido mismo que Isabel Stengers presenta las cosmopolíticas, la práctica conceptual de imaginación geográfica y antropológica nos lleva a situar la irrupción del cosmos a la política (Viveiros De Castro, Isabelle Stengers) como una práctica que subyace en lo que los Estados nacionales de Chile y Argentina están presentando como "conflicto Mapuche" y "terrorismo".

Como Carlos Porto Gonçalves señala en el prólogo del Atlas Mapuche, el mismo constituye un quiebre ontológico con el pensamiento geográfico moderno y se posiciona a nuestro modo de ver en una irrupción y transgresión que hace la perspectiva Mapu a las bases epistémicas o mejor, ontológicas al poner en cuestión lo que es el espacio geográfico, lo que es geográfico y cuáles son las divisiones ontológicas que son asignadas en ese proceso cuando estamos situados desde la perspectiva Mapu que trae a la coexistencia de todas las formas de vida como determinante geográfico y espacial y nos coloca de presente el concepto Mapuche de ixofillmogen.

Hirt (2012) señalaba que el proceso de mapeo que estaban haciendo era un proceso de reconstrucción, a partir de lo cual consideramos que los mapas al no existir como físicos en los soportes de papel y archivos, y estar viviendo en las memorias del despojo y al proponerse su elaboración como una reconstrucción se salen del entendimiento 
del espacio geográfico como una representación y se llevan a la construcción del entendimiento de un mapa que conecta tiempos históricos y ancestrales y que traen a hablar a otros seres aparentemente invisibles(Theriault,2015).

Los seres aparentemente invisibles complican el trabajo de los burócratas Thierhart (Op cit) en Filipinas. En el contexto Mapuche, se genera una tensión que desde el Estado nación se resuelve desde lo penal, cuando Pu Mapuche están refiriéndose a que es una cuestión política donde es necesario conversar, pero eso a lo que están refiriéndose de política no está solo pensado en nombre de los humanos, sino que está pensando a los seres aparentemente invisibles que habitan los espacios y que coexisten tal como la traducción de ixofillmogen de coexistencia de todas las formas de vida.

Por lo señalado por Hirt (2012) los mapas realizados por Mariman (2006) son los primeros mapas que presentan la continuidad trasandina del pensamiento geográfico Mapuche. Se hace con esto presente que esta orientación desde la perspectiva Mapu que propongo como de "nuestro norte es el este" se verá profundamente enriquecida en el año 2017 cuando se publica el atlas Mapuche (Melin y otros 2017) cuando esta orientación es retomada y además se asumirá con mayor propiedad y propondrá una crítica Mapuche que posiciona además la perspectiva Mapu, que ya vendrá siendo cuidadosamente y desde el que se refiere como el discurso ritual Mapuche, referida y tratada por Quidel (2012) quien ya presenta desde su conocimiento del mapuzungun una definición de Mapu que no la traduce ni de tierra ni de territorio sino que habla de espacio. Por lo anterior no estaríamos hablando de la traducción que se ha hecho cotidiana de Pu Mapuche ser los hijos de la tierra, sino estaríamos hablando de la gente que es de y está en los espacios.

No es menor este tipo de afirmaciones en tanto las mismas en su práctica se están desde lo que señalan $P u$ Mapuche, presentando como amenaza a los Estados nacionales y a las empresas, pero más que a estos actores específicos como aislados, se presentan como amenaza a las prácticas cartográficas del recorte y la calculación, que se encuentran implícitas en los proyectos nacionales que hablan del progreso y del desarrollo.

La prisión llamada de política del Longko Alberto Curamil y del Werken Alvaro Millalen ${ }^{7}$, se presenta como una cuestión que lleva a la reflexión torno a la subversión que provocan los procesos de mapeamento cuando van de la mano de la conquista, la inserción y la interlocución constante en el espacio judicial, en tanto en la relación dicha de intercultural el mismo espacio judicial se convierte en campo de equívocos.

\section{A modo de conclusiones}

Al ser una diferencia de perspectiva y no queriendo traducir una teoría sino haciendo que esta provoque historias que cuenten historias e interlocute con conceptos que piensen conceptos como el llamado que nos hace Donna Haraway el carácter perspectivista está en la emergencia de la perspectiva Mapu (Quidel 2012;Melin et al 2017) y en ese sentido caminan los trabajos de $P u$ Mapuche que interpelan en algún momento al perspectivismo ameríndio Quidel (2012) pero se sitúan desde el lugar de la perspectiva Mapu. La perspectiva Mapu está todo el tiempo en confrontación con la perspectiva del recorte y la calculación del Estado nación, así como del llamado del Estado a que las demandas se encuadren en sus recortes aparece interpelado por el geoposicionamiento ancestral que trae la perspectiva Mapu, los Pewma, a Pu longko, a Pu newen, a Pu Geh.

Al presentar espacios continuos en conexión, sin responder a la lógica de medición y calculación de recortes estato céntricos los mapas Pu Mapuche subvierten el espacio

7 El Longko Alberto Curamil y el Werken Alvaro Millalen fueron absueltos el día 13 de diciembre del presente año, siendo condenados a su vez por el mismo caso Victor Llanquileo y José Cáceres, dejando así de manifiesto una práctica de deslegitimización a las demandas $P u$ Mapuche que se hacen en el espacio judicial que instala verdades al imponer condenas. 
socialmente construído. Colocan de presente la perspectiva Mapu que no solo es representación, sino que se hace visible para pelear y luchar, emergiendo para incomodar a los burócratas y remitir terrenos vistos como potencialmente explotables al servicio del progreso y del desarrollo a la casa refugio de no humanos y ancestros humanos, que hacen parte de las demandas y cuya agencia necesita y se exige su reconocimiento.

El Longko Curamil y su familia nacieron en lo que hoy se llama Ercilla, allí desde siempre estuvieron inmersos en las luchas y retomadas enmarcadas en la reconstrucción como pueblo nación. Producto de esas luchas y de la presión el Estado decide comprar terrenos e adjudicarles no en Ercilla sino en Curacautin, de allá no es su tuwün (Digiminiani,2011) pero parece que los ancestros son rizomáticos en su visión de parentesco, porque llegaron a Curacautin retomando la toponimia ancestral y llamando del Lof Radalko y el Longko Curamil afirma haber soñado con los nombres de los lugares y haber sido bien recibido por los dueños del mismo en sus Pu pewma.

Existe según Pu Mapuche intentos de relacionar las luchas Pu Mapuche con las luchas de las guerrillas colombianas, así como con la Eta, como emergió en un juicio donde le fue preguntado a la perito arqueóloga Nuriluz Hermosilla si así como ella apoyaba lo que hacía el Pueblo Mapuche, entonces si ella también estaba de acuerdo con lo que hace el Estado Islámico y la ETA:

¿La pregunta que quiero hacer es porque usted ha señalado que la recuperación del Mapuche está en la recuperación del territorio y las leyes y lo que hacen dice en relación con el cariño que ellos le tienen a la tierra, es decir esta posición que usted nos ha explicado conforme al estúdio que usted hizo, significa que usted también apoya, las recuperaciones que se hacen en el corazón del Pueblo vasco, del estado islámico, eso tiene justificación entonces?

Con las cuestiones anteriores se pone de presente que los equívocos que se presentan en el espacio judicial ponen de presente a su vez enunciados que condenan y marcan los cuerpos Pu Mapuche a través de asociaciones arbitrarias, así como señalan Pu Mapuche que son cuestiones que se presentan como intentos de deslegitimar las formas de autodefensa propias de Pu Mapuche y las demandas por la autodeterminación como un derecho enmarcado no solo en las conversaciones que se tienen con ancestros - Pu Longko y el histórico de encuentros diplomáticos llamados de parlamentos sino que hoy reposan en innumerables instrumentos que en el espacio judicial y reconocen el derecho a la autodeterminación de los pueblos.

Para finalizar consideramos que los encuentros y urgencias que Pu Mapuche hoy están colocando de presente están atravesados por la prisión y el encarcelamiento que se amplía en el equívoco y malentendido cuando el Estado nación llama de comuneros, de zona roja, zona de conflicto y terrorismo a lo que Pu Mapuche refieren como Presos políticos Mapuche y un proceso de reconstrucción como pueblo nación.

\section{Referencias bibliográficas}

Arrate,Jorge y Llaitul,Hector. (2012). Weichan. Conversaciones con un weychafe en la prisión politica. Santiago de Chile. CEIBO, 2012

Becerra et al. (2017). Mapun kimün. Relaciones mapunche entre persona, tiempo y espacio. Santiago de Chile. Ocho Libros editores.

Calbucura, J \& F. Le Bonniec (eds.) (2009) Territorio y territorialidad en contexto post-colonial. Estado de Chile - Nación mapuche. Working Paper Series 30 Ñuke Mapuförlaget

Correa, Martin y Mella,Eduardo. (2009). El territorio Mapuche de Malleco: Las razones del Illkun. Temuco. Observatorio de derechos de los pueblos indígenas. 
Clastres, Pierre [1980](2004). Arqueologia da violência: pesquisas de antropologia política. Cosac \& Naify.

Course,Magnus. (2011). O nascimento da Palavra: linguagem, força e autoridade ritual mapuche. Revista de Antropología. (Número 2,v.54)

Course,Magnus. (2008). Estruturas de diferença no palin, esporte mapuche. Mana. (vol.14, n.2), pp.299- 328.

Di Giminiani, Piergiorgio. (2015). The becoming of ancestral land: Place and property in Mapuche land claims. American ethnologist. (Vol. 42, No. 3), pp. 490-503.

Di Giminiani, Piergiorgio. (2013). The contested rewe: sacred sites, misunderstandings and ontological pluralism in Mapuche land negotiations. Journal of Royal Anthropological Institute (Número 19, v. 3). Pp. 527-544.

Elden,Stuart. (2013) The Birth of Territory. University of Chicago. Chicago Press.

Elden,Stuart. (2010) Land, terrain, territory, Progress in Human Geography. (número 34. V.6). Pp. 799-817.

Elden, Stuart. (2009) Terror and Territory: The Spatial Extent of Sovereignty. Minnesota. Minnesota Press

Foerster, Rolf y Montecino, Sonia. (1988). Organizaciones, Líderes, y Contiendas Mapuches (19001970). Santiago de Chile. Ediciones Centros Estudios de la Mujer (CEM)

Goldman,Marcio.1999. A Experiência de Lienhardt: Uma Teoria Etnográfica da Religião. (Número 19, v. 2), Religião e Sociedade. Pp.9-30.

Harvey, David. (2004) O novo imperialismo. Tradução: Adail Sobral e Maria Stela Gonçalves. São Paulo. Edições Loyola.

Hirt,Irene. (2012). Mapping Dreams/Dreaming Maps: Bridging Indigenous and Western Geographical Knowledge. (No.2,V.47). Pp. 105-120.

Kopenawa, David.; Albert, Bruce. (2015). A queda do céu: palavras de um xamã yanomami. São Paulo: Companhia das Letras.

Le Bonniec, Fabien y Nahuelcheo, Pamela (2017). La mediación lingüístico-cultural en los tribunales en materia penal de la Araucanía, Revista de Llengua i Dret, Journal of Language and Law, núm. 67, 2017, p. 279-293.

Le Bonniec, Fabien (2008). Crónica de un juicio antiterrorista contra los dirigentes mapuche. Luchas indígenas y trayectorias poscoloniales, (107-138) (Santamaría, Bosa \& Wittersheim),Bogotá,Colombia. Editorial Universidad del Rosario.

Le Bonniec, Fabien. 2018. Un antropólogo inocente en búsqueda de exotismo en las cortes de justicia: Reflexiones acerca de las posibilidades de llevar una etnografía del campo jurídico en contexto intercultural en el sur de Chile. (pp. 151-167). Binimelis et al (Coord) Abriendo el diálogo Interdisciplinar, Temuco, Editorial UCT.

Melin et al. (2017). MAPU CHILLKANTUKUN ZUGU: Descolonizando el Mapa del Wallmapu, Construyendo Cartografía Cultural en Territorio Mapuche. Temuco, Pu Lof Editories ltda. Serie Mapuche Kimün

Melin. et al (2015). Az Mapu. Una aproximación al Sistema Normativo Mapuche desde el Rakizuam y el Derecho Propio. Instituto Nacional de Derechos Humanos.

Marimán et al. (2006) j...Escucha, winka...! Cuatro ensayos de Historia Nacional Mapuche y un epílogo sobre el futuro. Santiago de Chile. LOM Ediciones.

Nahuelpán, Hector. (2012). Formación colonial del Estado y desposesión en Ngulumapu. (123156). Ta iñ fijke xipa rakizuameluwün. Historia, colonialismo y resistencia desde el País Mapuche. Nahuelpán, H. et al. (Coord.). Temuco: Ediciones Comunidad de Historia Mapuche.

Napoleon Valerie. (2013) Thinking About Indigenous Legal Orders. Provost R., Sheppard C. (Coord.) Dialogues on Human Rights and Legal Pluralism. Ius Gentium: Comparative Perspectives on Law and Justice, vol 17. Springer, Dordrecht

Napoleon,Valerie. (2009). Ayook: gitksan legal order, law, and legal theory. (Tesis Degree of Doctor of Philosophy) University of Victoria, Victoria,Canadá. 
Pairican,Fernando (2015) El nuevo ciclo de movilización mapuche en Chile: la emergencia de la CAM y el proyecto autonomista para una región plurinacional. Araucaria. Revista Iberoamericana de Filosofía, Política y Humanidades.(Año 17, no 34). Pp. 279- 301.

Pairican,Fernando. Malon (2014). La rebelión del movimiento mapuche 1990-2013. Santiago, Chile, Pehuén Editores

Pichinao,Jimena (2012).Todavía sigo siendo mapuche en otros espacios territoriales (Mapuchewkülekan kake Fütal mapu mew). Tesis (Mestrado em antropologia social) - Faculdade de Filosofia, Letras e Ciências Humanas, Universidade de São Paulo. São Paulo.

Painemal, Carlos (2008). Los Tratados celebrados por los Mapuche con la Corona Española, la República de Chile y la República de Argentina. Tesis (Doctorado Americanista). Facultad de Historia y Estudios Culturales de la Universidade Livre de Berlín.

Panelli, Ruth. Social geographies: encounters with Indigenous and more-than-White/Anglo geographies. (No.6,v.32). Pp.801-811

Pineda, César. Marrichiweu. Antagonismo e insubordinación por la tierra y la autonomía: el pueblo indígena mapuche en Chile: el caso de la Coordinadora Arauco-Malleco. México: UNAM, 2013. Tesis (Mestrado em Estudos Latino-Americanos)- Faculdade de ciências Políticas e Sociais, Universidade Autônoma do México, México, 2013

Quidel, José. (2012). La idea de "Dios" y "Diablo" en el discurso ritual mapuche Las resignificaciones de las categoría Dios y Diablo entre las autoridades socioreligiosas mapuche del territorio wenteche. Tesis (Mestrado em antropologia social). Faculdade de Filosofia, Letras e Ciências Humanas, Universidade de São Paulo. São Paulo.

Quidel,José. (2016). El quiebre ontológico a partir del contacto Mapuche Hispano. Chungara, Revista de Antropología Chilena. (No 4, Volumen 48). Pp.713-719.

Stengers, Isabelle (2018). A proposição cosmopolítica. Revista do Instituto de Estudos Brasileros. (v. 1),p. 442-464.

Schavelzon,Salvador (2016). Cosmopoliticas e ontologias relacionais entre povos indígenas e populações tradicionais na américa latina. Revista de Antropología. v. 59 n. 3 (2016)

Surralles, Alexandre. (2017). Human rights for nonhumans?. Hau: Journal of Ethnographic theory. (Número.7,v.3). Pp.211-235.

Theriault, Noah. (2017). A forest of dreams: Ontological multiplicity and the fantasies of environmental government in the Philippines. Political Geography (No 58). Pp. 114-227

Vera, Robustiano (1905). La pacificación de Arauco. Santiago de Chile. Imprenta El debate.

Viveiros De Castro,Eduardo. (2017). Sobre a noção de etnocídio, com especial atenção ao caso brasileiro. Disponible en: https://www.academia.edu/25782893/Sobre_a_noção_de_ etnoc\%C3\%ADdio_com_especial_atenção_ao_caso_brasileiro

Viveiros De Castro, Eduardo (2004). Perspectival Anthropology and the Method of Controlled Equivocation. Tipití: Journal of the Society for the Anthropology of Lowland South America: Vol. 2: Iss. 1, Article 1.

Viveiros De Castro,Eduardo. (2000). Atualização e contra-efetuação do virtual na socialidade amazônica: o processo de parentesco. Ilha, (n.1). Pp. 5-46.

Viveiros De Castro, Eduardo. [2009] (2018). Metafisicas canibais. São Paulo: Ubu Editora.

Zavala, José Manuel (2008). Los mapuches del siglo xviii: dinamica interétnica y estrategias de resistencia. Santiago de Chile, Chile. Editorial Universidad Bolivariana S.A

El Mostrador. (2018). Contra la geopolítica de la muerte, una geografía para la vida. El Mostrador. Disponible en: https://www.elmostrador.cl/noticias/opinion/2018/11/25/ contra-la-geopolitica-de-la-muerte-una-geografia-para-la-vida/ [Fecha de consulta: 26/11/2018]

Nuestras Voces. (2017). ¿te gusta la tierra? ¡comé tierra!. Nuestras Voces. Disponible en: http:// www.nuestrasvoces.com.ar/investigaciones/te-gusta-la-tierra-come-tierra/ [Fecha de consulta: 30/11/2017] 
La nación. (2017). La "machi", el oráculo mapuche de 16 años clave en el conflicto de Villa Mascardi. La nación. (2017). Dísponible en: https://www.lanacion.com.ar/politica/la-machi-eloraculo-mapuche-de-16-anos-clave-en-el-conflicto-de-villa-mascardi-nid2087276 [Fecha de consulta: 02/12/2017]

Bio Bio Chile. (2017). Comunidades mapuche se reúnen en fundo la romana para analizar conflicto con el estado. Bio Bio Chile. Dísponible en: https://www.biobiochile.cl/ noticias/2012/08/18/comunidades-mapuche-se-reunen-en-fundo-la-romana-paraanalizar-conflicto.shtml [Fecha de consulta: 01/11/2017]

RadioUdeChile. (2018). Lonco de comunidad Mapuche Raquem Pillan es encontrado muerto en Ercilla. RadioUdeChile. Disponible en: https://radio.uchile.cl/2019/01/01/loncode-comunidad-mapuche-raquem-pillan-es-encontrado-muerto-en-ercilla/ [Fecha de consulta: 01/01/2019 ]

Todos los rios libres. (2014). Comunicado Público: Pu Lof en resistencia del Pilmaiquén. Todos los rios libres. Disponible en: https://todoslosrioslibres.wordpress.com/2014/09/08/ comunicado-publico-pu-lof-en-resistencia-del-pilmaiken-alianza-territorialpuelwillimapu/ [Fecha de consulta: 15/9/2016] 


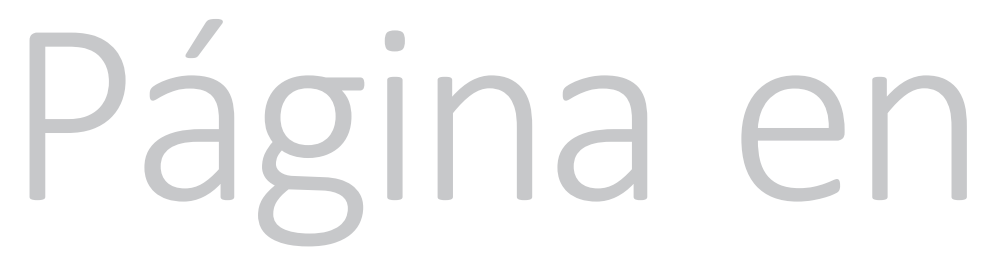

blanco 